\title{
Dádivas preciosas en marfil: la política del regalo en la corte omeya andalusí
}

\author{
Noelia Silva Santa-Cruz \\ Universidad Complutense de Madrid \\ Departamento de Historia del Arte I (Medieval) \\ nsilva@ucm.es
}

\begin{abstract}
RESUMEN
La magnificencia y la ostentación constituyeron parte fundamental de la política de prestigio implantada por los Omeyas en al-Andalus. Perpetuando la forma de actuación de los monarcas orientales, los soberanos andalusíes recurrieron con mucha frecuencia a presentes lujosos como expresión de su poder y autoridad, para lo cual instituyeron manufacturas artísticas estatales al servicio del príncipe. Dentro de estas industrias suntuarias, el taller áulico de marfil establecido en la ciudad palatina de Madīnat alZahrā' fue responsable de una de las producciones más sobresalientes y exquisitas de todo el Occidente medieval. Este artículo pretende, a partir de los restos materiales conservados, profundizar en el sofisticado discurso que, dentro del ámbito cortesano andalusí, se elaboró en torno al regalo como estructura de comunicación entre sujetos, y reflexionar acerca de las distintas categorías de obsequios eborarios comisionados por iniciativa regia en época califal.
\end{abstract}

Palabras clave: Al-Andalus, Córdoba, Califato, Artes suntuarias, Eboraria, Talleres de marfil, Política del regalo.

\section{Precious Ivory Presents: Politics of Gift in the Andalusi Umayyad Court}

\begin{abstract}
A fundamental part of the policy of prestige implemented by the Umayyad in al-Andalus was played through magnificence and ostentation. As the Eastern monarchs, the Andalusian rulers frequently relied on luxurious gifts as an expression of their power and authority; in this sense, they created a whole network of official artistic workshops at the service of the prince. Within these sumptuary industries, the ivory workshop established in the palatial city of Madinat al-Zahra' produced one of the most outstanding and exquisite productions of Medieval Western Europe. On the basis of the preserved pieces, this paper will study the sophisticated discourse about the gifts as a dialectic structure between subjects in the Andalusian court context. As well as a discussion on the different categories of ivory gifts commissioned by Royal initiative during the Caliphal period.
\end{abstract}

Key words: Al-Andalus, Córdoba, Caliphate, Luxury Arts, Ivory Works, Ivory Workshops, Politics of Gift. 
Regalar fue una actividad esencial en las principales cortes islámicas medievales. La sistematizada estrategia de actuación representativa y promocional del soberano implicaba escenificar fastuosamente una de sus principales virtudes: la generosidad. Precisamente uno de los noventa y nueve nombres de Allah lo designa como "el Generoso" (Corán 44:49). Esta elevada cualidad era extensible también a los califas, los cuales, como descendientes de Mahoma, formaban parte del distinguido grupo de "aquellos que están cerca de Dios" 1 . Una munificencia o generosidad regia, a menudo ensalzada por los panegiristas oficiales ${ }^{2}$, que era expresada públicamente mediante el acto de ofrecer como presente sumas en metálico o mercancías preciosas, siguiendo un modelo largamente experimentado con anterioridad por los emperadores romanos y bizantinos (largitio) $)^{3}$.

Ya el Profeta había practicado personalmente y fomentado el intercambio de regalos entre individuos al observar sus efectos beneficiosos sobre las relaciones humanas $^{4}$. Según las tradiciones orales preservadas en la literatura de regalos, Mahoma no solo ofreció obsequios a otros a lo largo de su vida, sino que también los aceptó, compensando siempre al generoso con un presente mejor a cambio. Incluso su uso de las dádivas fue ocasionalmente mucho más sofisticado, utilizándolas como un recurso para abrir puertas y almas que parecían cerradas e inaccesibles. Desaprobaba no obstante los regalos utilizados como sobornos ( $r a s h w a)$, aunque la frontera que separa un soborno y un regalo legalmente permisible resulta a veces muy difícil de definir ${ }^{5}$.

En el mundo islámico los obsequios suntuosos fueron una parte integral de la estructura social y política del Estado 6 . Su importancia se evidencia en el lenguaje, a través de las diversas y sutiles palabras que existen en árabe para hacer referencia al término "regalo". En esa lengua existen dos vocablos bien diferenciados para hacer referencia a un presente: "hiba" y "hadiyya". Según las fuentes legales islámicas, hiba representa un contrato por medio del cual la propiedad personal es voluntaria-

1 S. BLAIR, "On Giving to Shrines: 'Generosity Is a Quality of the People of Paradise", L. KOMAROFF (ed.), Gifts of the Sultan: The Arts of Giving at the Islamic Courts, New Haven, 2011, p. 51.

2 Vid. como ejemplo los versos que el poeta Ahmad ibn 'Abd Rabbihī dedica a 'Abd al-Rahmān III en IBN HAYYĀN, Crónica del califa Abdarrahman III an-Nasir entre los años 912 y 942 (al-Muqtabis V), traducción, notas e índices por M.J. VIGUERA y F. CORRIENTE, Zaragoza, 1981, pp. 104 y 117.

3 Vid. M. CORBIER, "Liberalitas, largitio", Brill's New Pauly. Encyclopaedia of the Ancient World, vol. 7 , Leiden-Boston, 2005, pp. 487-490, y "Munificentia", Brill's New Pauly. Encyclopaedia of the Ancient World, vol. 9, Leiden-Boston, 2006, pp. 297-299.

4 Vid. Book of Gifts and Rarities (Kitāb al-Hadāyā wa ak-Tuhaf), trad. G.A.H. AL-QADDŪMĪ, Cambridge, 1996, pp. 63-64.

5 Ibid., p. 4.

6 Para el rol y el significado del intercambio de regalos en los ámbitos islámico y bizantino durante la Tardoantigüedad y Edad Media, vid. G. VIKAN, Gifts from the Byzantine Court, Washington DC, 1980; A. CUTLER, "Les échanges de dons entre Byzance et l'Islam (IX'̀-Xİ̀ siècles)", Journal des Savants (JanvierJuin 1996), pp. 51-66, y "Significant Gifts: Patterns of Exchange in Late Antique, Byzantine, and Early Islamic Diplomacy", Journal of Medieval and Early Modern Studies, 38, 1 (2008), pp. 79-101, y "The Empire of Things: Gifts Exchange between Byzantium and the Islamic World", Record of Activities and Research Reports, June 1999-May 2000, Washington DC, 2000, pp. 67-70, y "Gifts and Gift Exchange as Aspects of the Byzantine, Arab, and Related Economies", Dumbarton Oaks Papers, 55 (2001), pp. 247-278, y "The Enduring Present: Gifts in Medieval Islam and Byzantium”, L. KOMAROFF (ed.), op. cit., 2011, pp. 79-90; y A. SHALEM, "Objects as Carriers of Real or Contrived Memories in a Cross-cultural Contex", Mitteilungen Zur Spätantiken und Byzantinischer Kunstgeschichte, 4 (2004), pp. 101-117. 
mente transferida de un individuo a otro sin la expectativa de recibir nada en contraprestación, mientras la palabra hadiyya, por el contrario, obliga al receptor a ofrecer algo a cambio ${ }^{7}$. Para el antropólogo francés Marcel Mauss (1872-1950), pionero en los estudios sobre el regalo con su obra Ensayo sobre el don, publicado por primera vez en 1925, los obsequios forman parte de un sistema tripartito consistente en dar, recibir y dar de nuevo ${ }^{8}$. Por tanto, a la presunta libre y desinteresada naturaleza del regalo se le añadirían con frecuencia las nociones contrapuestas de obligatoriedad y

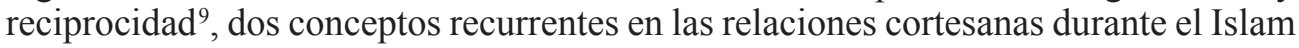
medieval.

Además del léxico, el otro elemento que denota la destacada implantación del regalo en la sociedad islámica medieval fue el desarrollo específico de un interesante género literario dedicado a describir regalos y "rarezas" 10 del que se tiene noticia ya desde el s. IX, y cuyo ejemplo más célebre lo constituye el libro redactado en el s. XI en el entorno de la corte fatimí, traducido al inglés con el título Book of Gifts and Rarities $^{11}$.

Al igual que sus rivales abbasíes, fatimíes, y sus antecesores omeyas, los califas andalusíes participaron del entusiasmo desmedido por los regalos. Algunas de estas espléndidas dádivas pueden rastrearse en las fuentes literarias y también, aunque con menos frecuencia, en la cultura material: ropas de honor inscritas con el nombre del gobernante salidas del tiraz palatino, deslumbrantes piedras preciosas, selectas piezas de joyería, armas de parada... ${ }^{12}$. A veces estos suntuosos regalos incluían también seres vivos (esclavos, animales exóticos, cabalgaduras o aves de presa), e incluso se documentan exquisitos productos de naturaleza perecedera como comida, especias, dulces o aromas. De esta delicada variedad de efímeros presentes solo algunos de los recipientes que los portaban han sobrevivido.

Un ejemplo excepcional de tales contenedores de lujo lo constituye el espléndido grupo de objetos en marfil califales que ha llegado hasta nosotros producidos en los talleres áulicos cordobeses ${ }^{13}$. Estos objetos fueron en origen una parte importante del regalo, pero no el regalo mismo. La presentación de los obsequios era vigilada con mimo, por lo que las dádivas eran empaquetadas cuidadosamente e incluso a veces se

7 Book of Gifts and Rarities, op. cit., 1996, p. 4; F. ROSENTHAL, "Hiba", B. LEWIS, V.L. MÉNAGE, Ch. PELLAT y J. SCHACHT (eds.), The Encyclopaedia of Islam, vol. III, Leiden, 1979, pp. 342-344.

8 M. MAUSS, Ensayo sobre el don: forma y función del intercambio en las sociedades arcaicas, Buenos Aires, 2009.

9 Hilsdale, siguiendo los estudios clásicos de Mauss, ha señalado la contradicción que encierra la acción de regalar, ya que su supuesta naturaleza generosa, voluntaria y desinteresada se complementa con las ideas de obligación y reciprocidad. En su opinión es necesario acudir al término "prestación" para resolver esta ambigüedad semántica. Vid. C.J. HILSDALE, "Gift”, Studies in Iconography, 33 (2012), pp. 171-178 [171182].

10 El término "rarezas" (tuhaf) alude a objetos curiosos o exóticos utilizados habitualmente como lujosos obsequios. Vid. Book of Gifts and Rarities, op. cit., 1996, pp. 8 y 439.

11 Ibid.

12 Tómense como ejemplo las descripciones vertidas en la cronística oficial. Para el período califal vid. principalmente IBN HAYYĀN, op cit., 1981, e IBN HAYYĀN, Anales platinos del califa de Córdoba alHakam II por 'Isà Ibn Ahmad al-Razi (360-364 H.), trad. E. GARCÍA GÓMEZ, Madrid, 1967.

13 Para un estudio pormenorizado de este selecto grupo vid. N. SILVA SANTA-CRUZ, La eboraria andalusí. Del Califato omeya a la Granada nazarí (BAR International Series 2522), Oxford, 2013, cap. II. 
envolvían en telas. Estos objetos eborarios a los que me refiero ejercieron como magníficos y suntuosos estuches para presentar ante el destinatario, tal y como señalan algunos epígrafes incluidos en ellos ${ }^{14}$, apreciadas y carísimas sustancias aromáticas importadas del Lejano Oriente a través de las diferentes rutas de las especias, así como piedras preciosas y/o joyas.

Los estuches de presentación en ricos materiales complementaban y aumentaban el valor monetario del obsequio y fueron concebidos con una voluntad de perdurabilidad, probablemente para sobrevivir y seguir siendo utilizados una vez que las fragancias se hubieran consumido o que las piedras preciosas que contenían se hubiesen utilizado. Además, complementaban perfectamente al regalo principal pues no solo eran portátiles y extraordinariamente bellos, sino que tenían un alto precio -el valor económico de la dádiva en su conjunto importó mucho- $\mathrm{y}$, al mismo tiempo, eran "raros" o "llamativos". En este caso esa rareza o atracción estaba relacionada con el carácter exótico de la materia prima elegida ${ }^{15}$.

En al-Andalus en época califal, se pueden distinguir básicamente dos categorías de obsequios eborarios comisionados por iniciativa regia. Un primer grupo de ejemplares está relacionado con la actividad oficial y protocolaria del soberano como representante del Estado omeya. En este ámbito, los recipientes de marfil eran utilizados como presentes de honor $\left(j i l^{\prime} a\right)^{16}$, a través del ejercicio público de una de las principales virtudes del monarca, su munificencia o generosidad, cualidad ya aludida al inicio de este trabajo. Estos regalos, dotados de un alto valor representativo, como expresión del poder califal, formaron parte habitual de la práctica diplomática, incorporándose a la parafernalia oficial instituida para agasajar a gobernantes o delegaciones extranjeras visitantes, así como para acompañar a las embajadas que viajaban a otros territorios. El presente o regalo era indispensable en las relaciones entre cortes ya que actuaba como signo de paz y concordia, al generar un sentimiento de cordialidad que distendía el clima de encuentro y contribuía a crear un marco propicio para la negociación ${ }^{17}$. Como ha señalado el profesor F. Valdés:

"los regalos poseían un valor real, como objetos preciosos que solían ser; uno político, porque el precio de lo ofrecido venía a denotar el interés de quien lo enviaba; y, entre algún que otro mensaje más, uno propagandístico. Eran una manifestación de la

14 Baste recordar la parte final de la célebre inscripción rimada que ornamenta el borde inferior de la cubierta de la píxide de la Hispanic Society of America, Nueva York: “(...) Soy envase para almizcle, alcanzor y ámbar gris" (ibid., pp. 208-210, nº 8).

$15 \mathrm{Su}$ ausencia en estado bruto en Europa, así como su obtención en lejanos territorios, que implicaba un dilatado proceso de transporte, sumado a su belleza intrínseca, fueron los principales condicionantes que convirtieron esta sustancia ya desde la Antigüedad en una demandada materia prima. Todo ello contribuyó a generar un aura de mito en torno al elefante promoviendo sus conexiones áulicas e imperiales y destinando el material extraído de sus defensas al contexto palaciego y a la esfera regia. Vid. A. SHALEM, The Oliphant. Islamic Objects in Historical Context, Leiden-Boston, 2004, pp. 85-88.

16 En relación con este término vid. X. BALLESTÍN, "Jil'a y monedas: el poder de los Banū Marwān en el Magrib al-Aqsā”, Al-Qantara, XXVII, 2 (2006), pp. 391-415.

17 M.E. DÍEZ JORGE, "Misivas de paz en las relaciones diplomáticas: regalos y presentes entre los reinos”, F. TORO CEBALLOS y J. RODRÍGUEZ MOLINA (eds.), III Estudios de Frontera: Convivencia, defensa y comunicación en la frontera, Jaén, 2000, pp. 219-233. 
riqueza de quien los hacía, porque traducía la habilidad de sus artesanos, la calidad de su técnica y la singularidad de su diseño" ${ }^{18}$.

Una actuación, esta de ofrecer dádivas, que se remonta al Próximo Oriente Antiguo ${ }^{19} \mathrm{y}$ de la que se esperaba siempre reciprocidad. Es decir, existía la exigencia implícita de devolver los regalos recibidos, lo que originaba un intercambio de presentes teóricamente voluntarios pero en realidad entregados y remitidos por obligación como un formalismo entre delegaciones. Los regalos devueltos debían ser similares a los recibidos, y esto desataba la rivalidad entre cortes, buscando la dádiva más ostentosa e impresionante como un elemento adicional en la espectacular parafernalia áulica encaminada a impactar y anonadar a los adversarios o aliados políticos.

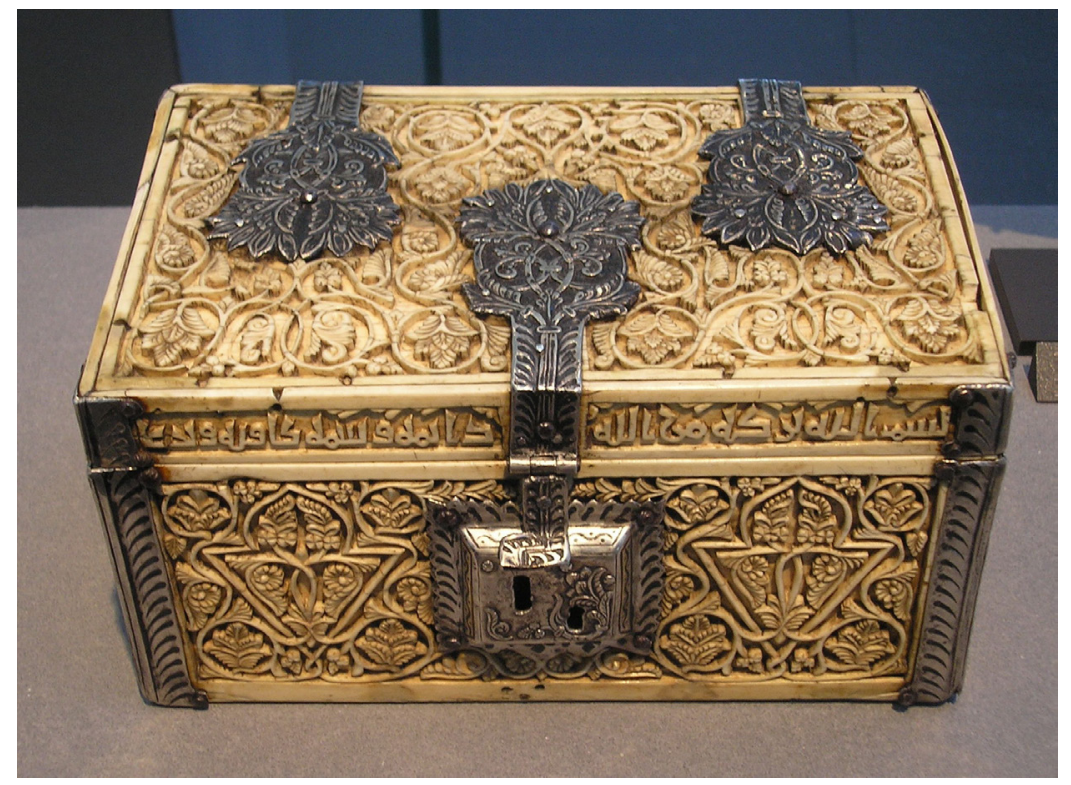

Fig. 1. Arqueta, Musée du Louvre, París (propiedad del Musée des Arts Décoratifs, París), h. 965-966 (Foto: Musée du Louvre).

Los cronistas andalusíes describen con minuciosidad estos fastuosos regalos protocolarios, muchos de ellos elaborados en colmillo de elefante. Destaca entre los mismos el célebre obsequio remitido en el año 934 por el primer califa de Córdoba, 'Abd al-Rahmān III, al príncipe beréber norteafricano Mūsa b. Abī l-'Āfiya, por estar integrado por un elevado número de recipientes de marfil, tanto píxides como

18 F. VALDÉS FERNÁNDEZ, “De embajadas y regalos entre califas y emperadores”, Awraq, 7 (2013), p. 34. Vid. también del mismo autor "Manufacturas palatinas, objetos de corte, regalos de embajada en la Córdoba omeya", C. SCHMIDT ARCANGELI y G. WOLF (eds.), Islamic Artefacts in the Mediterranean World. Trade, Gift, Exchange and Artistic Transfer, Venecia, 2010, pp. 63-70.

19 Vid. M. MORONY, "Gift Giving in the Iranian Tradition", L. KOMAROFF (ed.), op. cit., 2011, pp. $32-47$. 
arquetas, ninguno de los cuales desafortunadamente se ha conservado ${ }^{20}$. Algunos de los que sí han llegado hasta nosotros debieron estar pensados para satisfacer las necesidades representativas y de aparato de la corte, especialmente aquellos que no incorporan dedicatoria personal, sino una leyenda neutra, que permitía utilizarlos de forma polivalente, como la arqueta propiedad del Musée des Arts Décoratifs de París, adquirida en la venta del coleccionista Albert Goupil (1840-1884), ahora en depósito en el Musée du Louvre ${ }^{21}$ (Fig. 1).

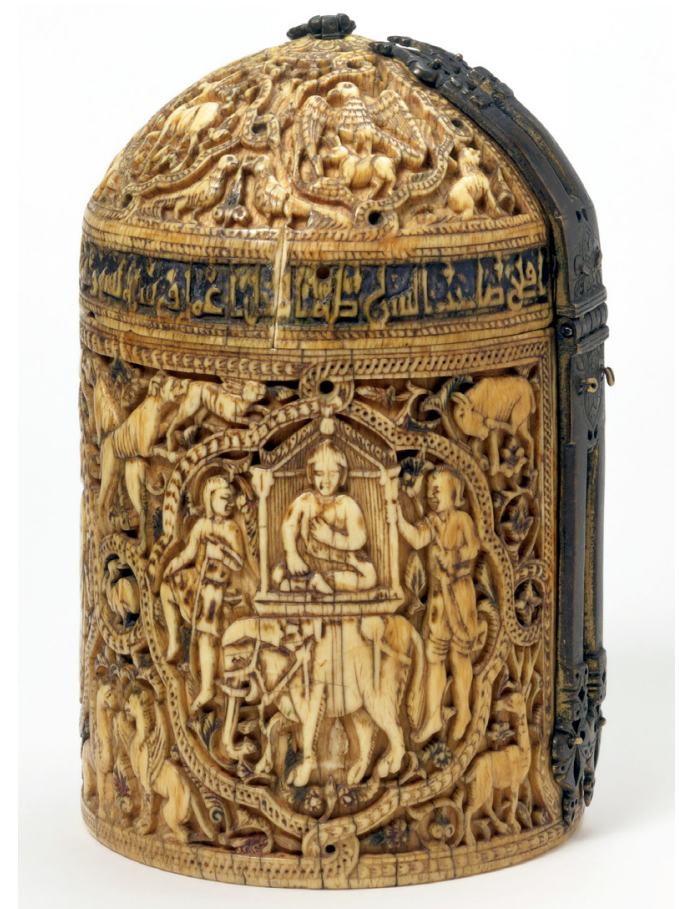

Fig. 2. Píxide dedicada a Ziyād ibn Aflah, Victoria and Albert Museum, Londres, año 969970 (Foto: Victoria and Albert Museum).

Asimismo este tipo de presentes de honor eran habituales en la actividad política ordinaria y de ámbito estatal, acomodándose a una amplia variedad de propósitos, muchas veces complejos y sofisticados. El soberano distribuía estas dádivas entre altos dignatarios de la corte, destacadas personalidades tanto del ámbito civil como militar, en un gesto de privanza o distinción hacia sus más eficaces colaboradores, en el marco de las complejas relaciones de clientela ${ }^{22}$. Se ofrecerían como espontáneas muestras de respeto o cortesía hacia un subordinado, o tal vez podrían incorporar una

\footnotetext{
20 IBN HAYYĀN, op. cit., 1981, pp. 264-265.

21 N. SILVA SANTA-CRUZ, op. cit., 2013, pp. 211-212, nº 10.

22 S. MAKARIOU y G. MARTÍNEZ GROS, “Arte y política en al-Andalus", Las Andalucias de Damasco a Córdoba, París, Institut du Monde Arabe, 2000, p. 76.
} 
intencionalidad más profunda y difícil de definir, constituyendo el pago por favores personales, o ejerciendo como recompensas de carácter público para premiar una actuación militar o política. No se descarta tampoco su destino ocasional como presentes propiciatorios, dirigidos a captar voluntades y asegurar lealtades ${ }^{23}$. El ejemplo paradigmático de esta categoría lo constituye la píxide dedicada a Ziyād ibn Aflah (Victoria and Albert Museum, Londres) (Fig. 2), regalada por el califa al-Hakam II en el año 969-970 al jefe de la policía judicial de Córdoba (sāhib al-surta), un importante cargo perteneciente a la administración civil omeya, al que el soberano debió obsequiar como premio por alguna actuación que le agradara o beneficiara especialmente ${ }^{24}$. Como en la mayoría de los objetos del grupo estatal, en la píxide de Ziyād se observa una insistencia en un vocabulario visual tomado del ciclo de temas reales (califa en majestad, halconero a caballo, leones, águilas...), unas imágenes elegidas deliberadamente para articular un sistema visual de propaganda política, que pretendía otorgar un carácter marcadamente "oficial" al recipiente. A través de esta iconografía, los objetos regalados remitirían al gobernante o incluso podrían actuar ante quien los recibía como sustitutos o evocaciones de la presencia real o efectiva del califa ${ }^{25}$. Esta presencia virtual del príncipe se reforzaría además a través de la inscripción conmemorativa, que actuaba como marchamo regio, y que mencionaba a veces expresamente el nombre del monarca.
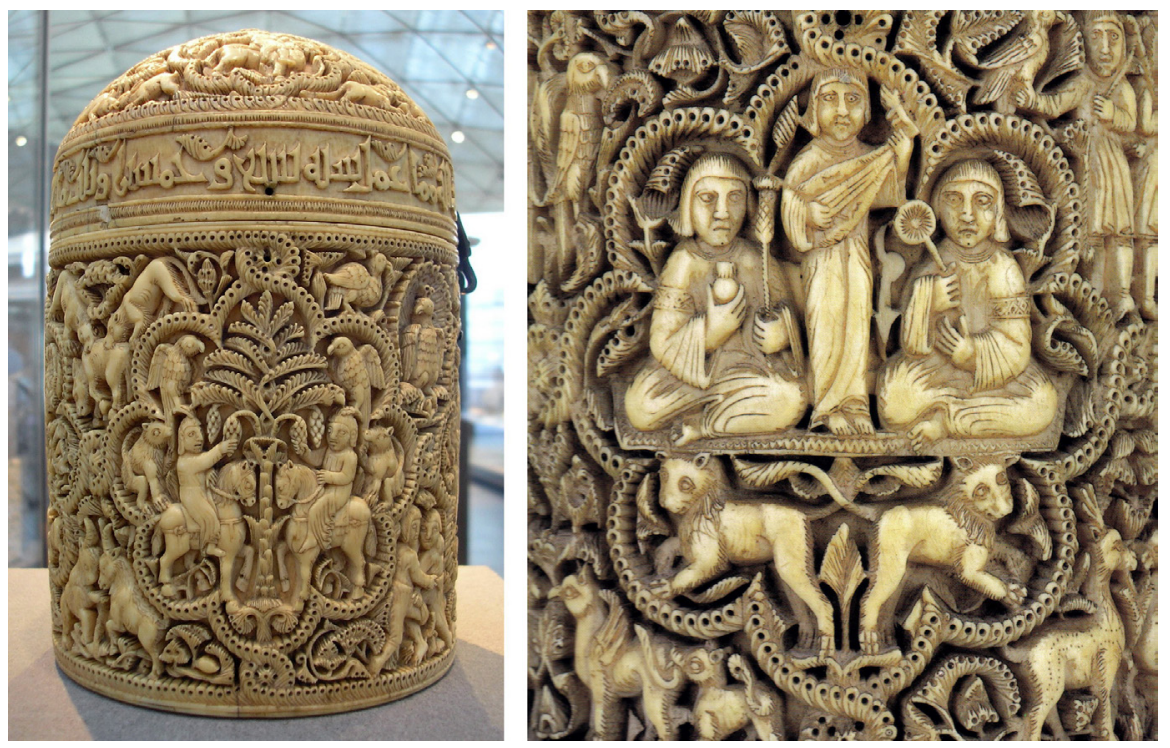

Fig. 3. Píxide dedicada al príncipe al-Mugīra, Musée du Louvre, París, año 968: a) Vista general; b) Detalle de un medallón (Fotos: Musée du Louvre).

23 Vid. N. SILVA SANTA-CRUZ, op. cit., 2013, pp. 219-223.

24 Para esta pieza vid. ibid., pp. 219-223, nº 14.

25 E.R. HOFFMAN, "Pathways of Portability: Islamic and Christian Interchange from the Tenth to the Twelfth Century", Art History, 24 (2001), p. 26. 
Fuera del entorno de representación pública, un segundo conjunto de objetos de marfil reúne aquellas obras patrocinadas por el soberano para ser entregadas a miembros de su círculo íntimo o familiar, es decir, a otros individuos de estirpe real omeya y a personas de su entorno doméstico o afectivo inmediato, como esposas o favoritas. Se trata de regalos personales destinados a conmemorar ciertas festividades religiosas del calendario musulmán como la Fiesta de Ruptura del Ayuno ('Id al Fitr) o eventos anuales, como el Año Nuevo ${ }^{26}$, así como acontecimientos de índole más privada: matrimonios, alumbramientos, aniversarios, circuncisiones... De esta categoría conservamos interesantes ejemplos dentro de la eboraria califal.

Dentro de los presentes destinados a miembros de la familia omeya hay que aludir a la píxide regalada por al-Hakam II al menor de sus hermanos, al-Mugīra, en el año 968, hoy conservada en el Musée du Louvre (Fig. 3a) ${ }^{27}$, de controvertida interpretación iconográfica. Desconocemos la circunstancia en que el recipiente fue ofrecido al joven príncipe. Tal vez con ocasión de su aniversario o en relación con los obsequios que se intercambiaban entre parientes y amigos durante la Fiesta de Ruptura del Ayuno. En cualquier caso, creemos que el regalo resultaría por completo ajeno a los acontecimientos políticos que desembocarían en el trágico asesinato de al-Mugīra en el 976, con los que algunos autores lo han querido relacionar. Su programa decorativo no sería, como se ha señalado ${ }^{28}$, una llamada de atención encubierta, en forma de jeroglífico o clave, dirigida a este miembro de los Banū Marwān para disuadirle de una eventual conspiración contra la sucesión legítima de al-Hakam. Si bien no ha sido tomado en consideración con anterioridad, existe un dato objetivo en contra de esta hipótesis. La ejecución del recipiente dista de esos acontecimientos unos ocho años, un lapso temporal excesivo, en mi opinión, para poder sostener la conexión directa entre ambos hechos históricos. Muy probablemente por entonces ni siquiera estarían aún configuradas de facto las dos facciones políticas opuestas que lucharían por heredar el trono en los últimos años de la vida del califa ${ }^{29}$. Además, las noticias aportadas por las crónicas oficiales en el período en torno a la ejecución de la pieza se inclinan a nuestro favor, pues no reflejan ningún distanciamiento aparente entre el califa y su hermano menor, al-Mugìra, como con-

26 F. ROSENTHAL, op. cit., 1979, p. 343.

27 Para este recipiente vid. N. SILVA SANTA-CRUZ, op. cit., 2013, pp. 215-219, nº 13.

28 Vid. F. PRADO-VILAR, "Circular Visions of Fertility and Punishment: Caliphal Ivory Caskets from al-Andalus", Muqarnas, XIV (1997), pp. 19-41, esp. 21-30, y "Enclosed in Ivory: The Miseducation of alMughira", K. VON FOLSACH y J. MEYER (eds.), The Ivories of Muslim Spain. Papers from a symposium held in Copenhagen from 18th to the 20th of November 2003, vol. 2.1 de Journal of the David Collection (2005), pp. 139-163. Makariou sugiere una interpretación de las escenas asimismo en sentido metáforico, como referencia a una querella existente ya en ese momento en cuanto a la sucesión en el seno de la familia omeya (S. MAKARIOU, La pyxide d'al-Mughira, París, 2012, pp. 16-22).

29 En relación con el complot para hacerse con el poder por parte del hermano consanguíneo de al-Hakam II vid. E. LÉVI-PROVENÇAL, Histoire de l'Espagne Musulmane: Le Califat Umayyade de Cordoue (9151031), vol. II, París, 1950, p. 206; R. DOZY, Historia de los Musulmanes de España, vol. III, Madrid, 1984, pp. 117-124; K. SATO, "Los saqaliba y la corte en la segunda mitad del siglo X", A. TORREMOCHA SILVA y V. MARTÍNEZ ENAMORADO (eds.), Al-Andalus y el Mediterráneo en torno al año 1000. La época de Almanzor, Algeciras, 2003, pp. 107-108; y M. MAKARIOU, “Aux origines de la fitna, l'affaire al-Mughira: la mémoire refoulée d'un assassinat à la cour de Cordoue au X $\mathrm{X}^{\mathrm{e}}$ siècle”, Médiévales, 60 (2011), pp. 29-44. 
secuencia de posibles intrigas de este por el poder, sentándose siempre juntos y en armonía en las recepciones oficiales dispensadas con ocasión de las Fiestas de Ruptura del Ayuno y de los Sacrificios entre los años 971-974, período que documenta excepcionalmente la crónica de Ibn Hayyān ${ }^{30}$.

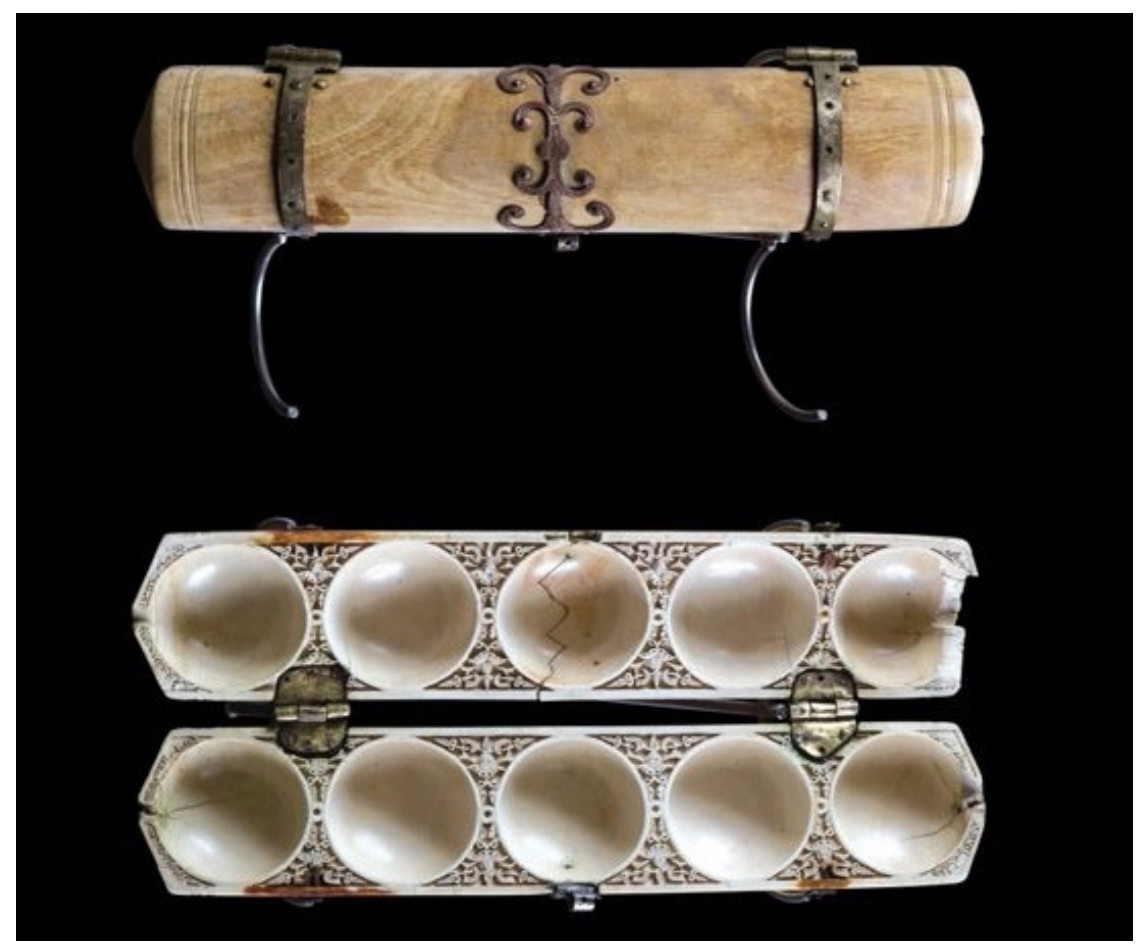

Fig. 4. Tablero de mancala dedicado a una de las hijas de 'Abd al-Rahmān III, Museo de Burgos, h. 950-961 (Foto: Museo de Burgos).

Existe igualmente otra incongruencia significativa en la teoría más divulgada hasta ahora. Los dos personajes representados varias veces en los medallones de la píxide (Fig. 3b), nunca podrían ser los hijos de al-Hakam II como se ha señalado ${ }^{31}$, pues en ese momento eran niños de corta edad. El príncipe 'Abd al-Rahmān tendría en esa fecha alrededor de siete años y Hishām tan solo tres ${ }^{32}$. Ni siquiera estaban en la pubertad, por lo que difícilmente se les podría representar como los adultos tallados

30 IBN HAYYĀN, op. cit., 1967.

31 F. PRADO-VILAR, op. cit. (1997), p. 38, y F. PRADO-VILAR, op. cit. (2005), pp. 141 y 147.

32 'Abd al-Rahmān había nacido en 962 y murió prematuramente en 969-970, con tan solo ocho años de edad, muy poco después de la elaboración del recipiente de marfil para su tío al-Mugīra. En 965, la concubina Subh dio a luz al segundo hijo varón del monarca, Abu '1- Walid Hishām que, como resultado del fallecimiento de su hermano uterino, llegaría a ser el heredero definitivo, sucediendo a su padre. Para la breve biografía infantil del príncipe 'Abd al-Rahmān, vid. M. MARÍN “Una vida de mujer: Subh”, M.L. ÁVILA y M. MARÍN (eds.), Biografias y género biográfico en el Occidente islámico, Madrid, 1997, pp. 434-435; y S. BLAIR 
en la pieza de marfil. En mi opinión, estas escenas contendrían diferentes alusiones estereotipadas al monarca acompañado de su hermano, destinario del objeto, tanto en su vida palatina como practicando diferentes pasatiempos, dentro de una iconografía principesca codificada y recurrente en la que resulta difícil advertir mensajes personalizados hasta tal extremo.

Varias princesas reales andalusíes fueron obsequiadas asimismo con lujosos objetos salidos del taller eborario estatal por iniciativa del califa ${ }^{33}$. Una hija de 'Abd al-Rahmān III recibió del monarca hacia mediados del s. X (960-961) el espléndido juego de mancala, hoy conservado en el Museo de Burgos (Fig. 4) ${ }^{34}$.
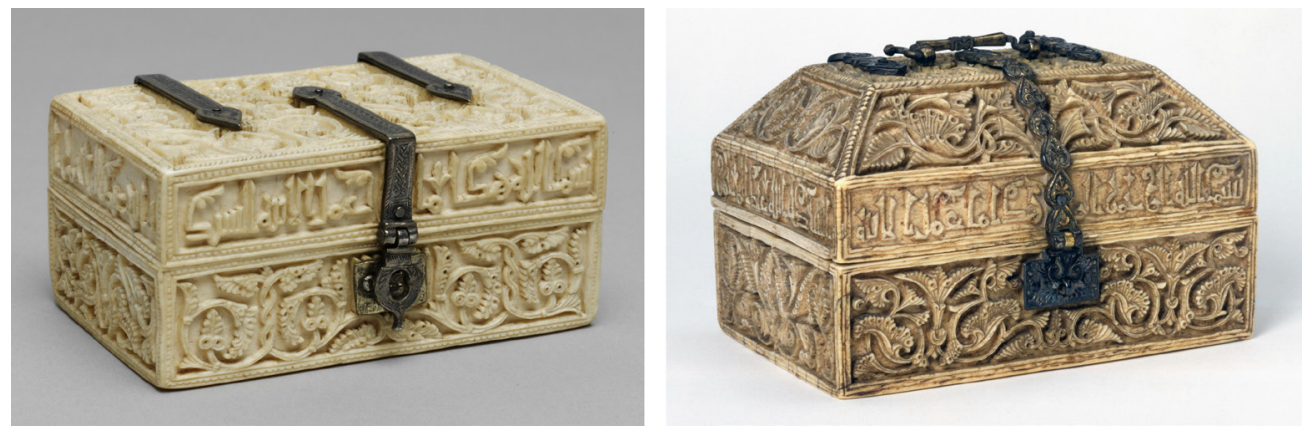

Fig. 5. Arquetas dedicadas a una hija de 'Abd al-Rahmān III, Victoria and Albert Museum, Londres, h. 962-965: inv. no 301/1866 (izquierda) y nº 580/1910 (derecha) (Fotos: Victoria and Albert Museum).

El sucesor en el trono de al-Nāsir, al-Hakam II (r. 961-976), fue especialmente dadivoso con sus parientes femeninas más cercanas en lo que respecta a regalos suntuarios en marfil. Según la crónica de Ibn Hayyān, 'Abd al-Rahmān III tuvo dieciséis hijas $^{35}$. Como consecuencia de una rotura en el manuscrito original, solo cuatro de los nombres de estas mujeres se han conservado: Saniyya, Salama, Wallāda y Hind. Para alguna de estas damas, anónima o mencionada en el texto, el califa encargó poco después de su acceso al trono un lote formado por dos cajas, ahora en el Victoria and Albert Museum de Londres (Fig. 5) ${ }^{36}$.

En el año 966 obsequió también a su hermana uterina, la princesa Wāllada, con un conjunto análogo de recipientes, constituido también por un par de pequeñas arquetas, cuasi gemelas, custodiadas en la actualidad en la iglesia parroquial de Fitero (Navarra)

\footnotetext{
"What the Inscriptions Tell Us: Text and Message on the Ivories from al-Andalus", K. VON FOLSACH y J. MEYER (eds.), op. cit. (2005), p. 90.

33 Una reflexión sobre los regalos áulicos en marfil destinados a mujeres en la corte omeya cordobesa en N. SILVA SANTA-CRUZ, "Ivory Gifts for Women in Caliphal Córdoba: Marriage, Maternity and Sensuality", Journal of Medieval Iberian Studies, 6, 1 (2014), pp. 103-125.

34 Para esta pieza vid. N. SILVA SANTA-CRUZ, op. cit., 2013, pp. 192-194, nº 1.

35 IBN HAYYĀN, op. cit., 1981, p. 24.

36 Para estos recipientes vid. N. SILVA SANTA-CRUZ, op. cit., 2013, pp. 194-198, nos 2-3.
} 
y en el Instituto Valencia de Don Juan (Madrid) (Fig. 6) ${ }^{37}$. Sus inscripciones conmemorativas repiten idéntica fecha y lugar de ejecución (año 966, taller de Madīnat al-Zahrā'), pero solo en la banda epigráfica de la primera caja, de mayor perímetro, se incluye el nombre del artífice (Jalaf). Estas piezas parecen ejecutadas por la misma mano y, al igual que las anteriores, pudieron funcionar conjuntamente, acoplándose tal vez una dentro de otra, dado el tamaño ligeramente superior del ejemplar navarro, al igual que sucede en otros ejemplos paralelos de los que tenemos noticia dentro del ámbito islámico medieval, como el suntuoso presente que Umm Ja'far, la esposa del califa abbasí al-Hādī, envió a Abū Yūsuf, el cual consistía en "a silver box which held two other silver boxes, each containing a different scent" ${ }^{38}$. En la configuración de estos regalos no solo se pretendía que el recipiente o envoltorio fuera de valor equiparable al objeto o substancia contenida en su interior, sino que muchas veces se trataba de mantener la expectación e incluso alimentar la imaginación e ilusión del destinatario mediante la clausura del recipiente con candados y cerraduras, incorporando incluso contenedores adicionales dentro del principal para dilatar el tiempo de apertura y añadir más impaciencia y excitación al descubrimiento del regalo ${ }^{39}$.
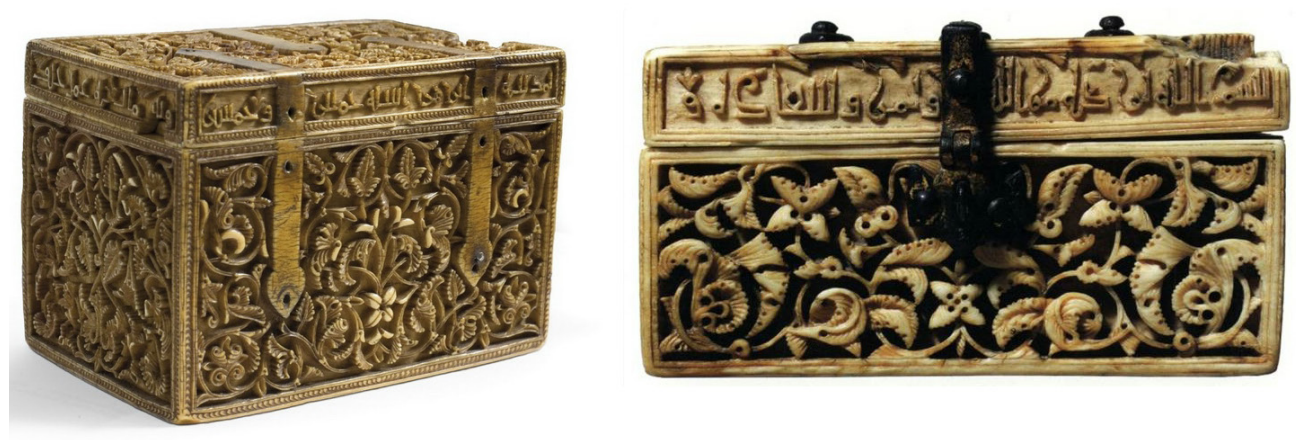

Fig. 6. Arquetas dedicadas a la princesa Wāllada, año 966. Izquierda: Arqueta de la iglesia parroquial de Santa María de Fitero, Navarra (Foto: Servicio de Patrimonio Histórico, Gobierno de Navarra); Derecha: Arqueta del Instituto de Valencia de Don Juan, Madrid (Foto: Municio).

Las hijas o hermanas del califa pudieron recibir estos espléndidos objetos agrupados en lotes como dádivas reales con ocasión de acontecimientos relevantes en su vida, pro-

37 Respecto a la identificación de la destinataria como Wallāda en las fuentes, vid. N. SILVA SANTACRUZ, "Nuevos datos para el estudio de dos piezas de eboraria califal: arquetas de la iglesia parroquial de Fitero y del Instituto Valencia de Don Juan", Anales de Historia del Arte, 9 (1999), pp. 27-33, y La eboraria andalusi, op. cit., 2013, pp. 204-205 y 207. Así como L. BARIANI “¿Fue Subh «la plus chère des femmes fécondes»? Consideraciones sobre la dedicatoria de las arquetas califales del Instituto Valencia de Don Juan y de la iglesia de Santa María de Fitero", Al-Qantara, XXVI, 2 (2005), pp. 299-316, y "Cajita de Fitero y cajita califal”, I. BANGO TORVISO (dir.), La edad de un reyno. Las encrucijadas de la Corona y la Diócesis de Pamplona, catálogo de la exposición (Pamplona, 2006), vol. I, Madrid, 2006, pp. 504-505, ns $152-153$.

38 AL-MAS'UDI, Meadows of Gold. The Abbasids, trad. y ed. P. LUNDE y C. STONE, Londres-Nueva York, 1989, p. 70. Citado en A. SHALEM, "Performance of the Objet", L. KOMAROFF (ed.), op. cit., 2011, p. 112.

39 Vid. A. SHALEM, op. cit., 2011, pp. 111-113. 
bablemente bodas o natalicios. La celebración de la boda era un momento culminante para estas mujeres de alto rango. Dicha ceremonia consistía en un acto jurídico, centrado en la firma del documento por el cual la mujer pasaba de la custodia del padre o tutor a la del marido. Un protocolo legal que tenía paralelamente una vertiente pública, constituida por una serie de celebraciones que incluían regalos, adornos y espléndidas fiestas ${ }^{40}$. Además, la adquisición y preparación por parte de la familia de la novia tanto de su ajuar personal como el de la vivienda conyugal, empleando las aportaciones económicas del contrayente y de su padre o valedor, era un requisito indispensable para la celebración del enlace ${ }^{41}$. Con frecuencia el matrimonio de las princesas reales excedía el contexto estrictamente familiar, para convertirse en una auténtica cuestión de estado gracias a la capacidad del compromiso nupcial para favorecer a través del mismo el establecimiento de vínculos amistosos o políticos ${ }^{42}$. Es posible que algunas de estas piezas fueran regaladas con ese fin, adquiriendo así un carácter semi-oficial.

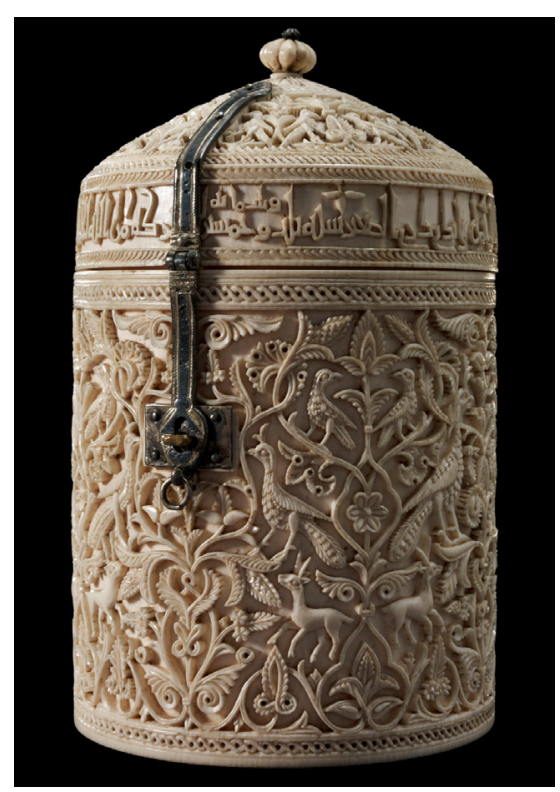

Fig. 7. Píxide dedicada a Subh, procedente de la Catedral de Zamora, Museo Arqueológico Nacional, Madrid, año 964 (Foto: Museo Arqueológico Nacional).

40 M. MARÍN, Individuo y sociedad en al-Andalus, Madrid, 1992, pp. 182-183.

41 M. MARÍN, Mujeres en al-Andalus, Madrid, 2000, pp. 432-33.

42 Vid. M. MARÍN, "Las mujeres de las clases sociales superiores. Al-Andalus desde la conquista hasta finales del Califato de Córdoba", M. VIGUERA MOLINS (ed.), La mujer en al-Andalus. Reflejos históricos de su actividad y categorías sociales. Actas de las V Jornadas de Investigación Interdisciplinaria, I: Al-Andalus, Madrid, 1989, pp. 109-111. Algunas fuentes hacen referencia a este tipo de matrimonios políticos. A título de ejemplo, podemos citar las bodas pactadas de las hermanas del emir andalusí al-Hakam I en IBN HAYYĀN, Crónica de los emires Alhakam I y Abdarrahmān II entre los años 796 y 847 [Almuqtabis II-1], trad. M.A. MAKKI y F. CORRIENTE, Zaragoza, 2001, p. 29. 
Las mujeres de la familia real andalusí fueron obsequiadas con estos espléndidos contenedores en marfil salidos del taller oficial como dádivas reales seguramente también al dar a luz un vástago. No solo el libro sagrado del Islam hace referencia a los hijos como riqueza y honor ${ }^{43}$, sino que los propios festejos nupciales entrañaban, además de ritos protectores y propiciatorios, un evidente componente de exaltación de la capacidad reproductora femenina ${ }^{44}$. Esta facultad de alumbrar descendientes fue una de las virtudes femeninas más ensalzadas en el Islam medieval, especialmente valorada en el caso de las damas de alta alcurnia y de las concubinas o esposas reales, ya que eran responsables directas de la continuidad dinástica, al contribuir a perpetuar la genealogía omeya. Dar a luz hijos varones era un feliz acontecimiento familiar, circunscrito ciertamente al ámbito privado, pero que en realidad atañía a la esencia misma de la institución califal, pues constituía el núcleo de la transmisión genealógica, otorgando así a las mujeres un papel trascendental dentro de la sociedad islámica ${ }^{45}$.

Las doncellas del harén también recibieron en la corte andalusí dádivas en marfil como obsequio del soberano, como demuestra la píxide de Zamora, hoy en el Museo Arqueológico Nacional (Fig. 7) ${ }^{46}$. La pieza fue encargada en el año 964 por el segundo califa de Córdoba, para agasajar a Subh, su concubina favorita, que dos años antes había dado a luz al hijo primogénito de al-Hakam II, el antes aludido príncipe 'Abd al-Rahmān ${ }^{47}$. Lejos de tratarse de un regalo de carácter maternal vinculado con el nacimiento del hijo primogénito del monarca, o de su hermano Hishām, como se ha señalado tradicionalmente ${ }^{48}$, me inclino más bien a entenderlo como un presente de carácter amoroso o íntimo entre amantes, al estar dotado de un atractivo matiz sensual, lindante con lo erótico, en conexión con la forma semiesférica de su cubierta que, como señala la poesía islámica coetánea, emularía la forma abultada y voluptuosa de un seno femenino. Idéntica comparación se encuentra presente, por ejemplo, en los versos del célebre poeta bagdadí Ibn al-Rūmi (836-896), dirigidos a una dama:

"Sus pechos son semejantes a curvadas cajitas de marfil, y posee unos dientes embellecidos con la hermosura de su perfecto orden Cuando los vieron aquellos que siempre andan por ahí hablando, dijeron: En ellos tienes las perlas de esas cajitas" ${ }^{\prime 4}$.

El tópico, que debió ser recurrente en Oriente, se transfirió a la literatura andalusí, como manifiestan estos versos, recogidos por el sabio cordobés Ibn al-Kattānī (h.

43 Corán XVIII, 39, 46; XXV, 74 y XXXIV, 35.

44 M. MARÍN, op. cit., 2000, p. 433.

45 M. MARÍN, Vidas de mujeres andalusies, Málaga, 2006, p. 142.

46 Vid. N. SILVA SANTA-CRUZ, op. cit., 2013, pp. 198-202, no 4.

47 Vid. supra, nota 32. Para una semblanza de Subh vid. M. MARÍN, op. cit., 1997, pp. 425-445.

48 Yo misma he publicado esta opinión varias veces, vid. N. SILVA SANTA-CRUZ, "Marfiles", A.E. MOMPLET MÍGUEZ, El arte hispanomusulmán, Madrid, 2004, p. 259, у op. cit., 2013, p. 201.

49 IBN AL-KHATĪB, Poesía árabe clásica. Antología titulada "Libro de la magia y de la poesía", ed. y trad. J.M. CONTINENTE FERRER, Madrid, 1981, p. 149, n 585. Este poema proporciona además un dato inédito de gran trascendencia para el conocimiento de la eboraria islámica medieval, pues corrobora que la tipología de píxide fue conocida y empleada ya en el califato abbasí, hacia mediados del s. IX. 
950-1029 $)^{50}$ en su antología poética titulada Kitab al-tashbihat min ash'ar ahl alAndalus (Libro de los símiles en los poemas de los andalusíes):

"Corremos, tímidas gacelas, de dos especies, bellezas con los ojos oscuros y claros. Con los senos resplandecientes, refinados, como cofres de marfil, y caderas estrechas $(\ldots)^{\prime 51}$.

La comparación se halla de nuevo presente en la inscripción rimada de la bella píxide conservada en la Hispanic Society of America, Nueva York, redactada en primera persona (Fig. 8):

"Mi aspecto es aspecto de gran belleza, seno de joven que conserva toda su turgencia..." ${ }^{52}$.

En este caso, al igual que sucede en el bote dedicado a Subh, el símil literario trasciende los límites de la retórica para convertirse en una efectista metáfora visual que se refuerza ante la semejanza existente entre el marfil y la delicada epidermis femenina, un paralelismo que se transmitió a la literatura islámica medieval a través de la poesía jahiliyya o precoránica, pero que está presente ya en composiciones profanas y religiosas de la Antigüedad, como la Odisea de Homero, o en los versos de extraordinaria belleza lírica del célebre Cantar de los Cantares ${ }^{53}$.

En definitiva, como hemos ido desgranando a través de estos exquisitos testimonios en marfil, el discurso del regalo en la corte andalusí fue extraordinariamente sofisticado, revelándose como un mecanismo de magnificencia regia ligado a la propia estructura estatal e íntimamente asociado al complejo universo de las relaciones tanto políticas como personales del califa. La iconografía de estos recipientes se manifiesta como un recurso visual privativo del soberano, pues se circunscribe a un repertorio limitado de imágenes-tipo, en el que se incluyen temas vegetales, zoomorfos y escenas principescas que se adaptan en función del destinatario, lo cual, sumado a la materia prima elegida, redunda en la exclusividad de la producción.

\footnotetext{
50 Médico personal de Almanzor y de su hijo al-Muzaffar, se vio obligado a emigrar a la taifa de Zaragoza como consecuencia del desencadenamiento de la fitna. Escribió tratados médico-científicos, fue experto en lógica y filosofía, además de un reputado literato, maestro de Ibn Hazm, el célebre autor del Collar de la paloma. Su escuela para formar jóvenes esclavas cantoras fue una de las más prestigiosas de al-Andalus. Vid. M. LOMBA FUENTES, La filosofía islámica en Zaragoza, Zaragoza, 1987, pp. 128-130, y M. CORTÉS GARCÍA, La música en la Zaragoza islámica, Zaragoza, 2009, pp. 22-23.

51 IBN AL-KATTĀNĪ, Kitab al-tashbihat min ash'ar ahl al-Andalus, ed. I. ABBAS, Beirut, 1981; $c f$. trad. W. HOENERBACH, Dichterische Vergleiche der Andalus-Araber, Bonn, 1973, pp. 135-136, y N. MOUFFOK, Estudio y traducción del Kitāb al-tashbīhāt de Ibn al-Kattān̄̄, tesis doctoral inédita, Universidad Complutense de Madrid, 2001.

52 J. FERRANDIS, Marfiles árabes de Occidente, vol. I, Madrid, 1935, p. 65, nº 9. Para la epigrafía, así como para las características técnicas y estéticas de este recipiente, vid. N. SILVA SANTA-CRUZ, op. cit., 2013, pp. 208-210, nº 8 .

53 Odisea 18, 196 y Cantar de los Cantares 7:5 y 5:14. Vid. A. SHALEM, op. cit., 2004, pp. 82-84.
} 


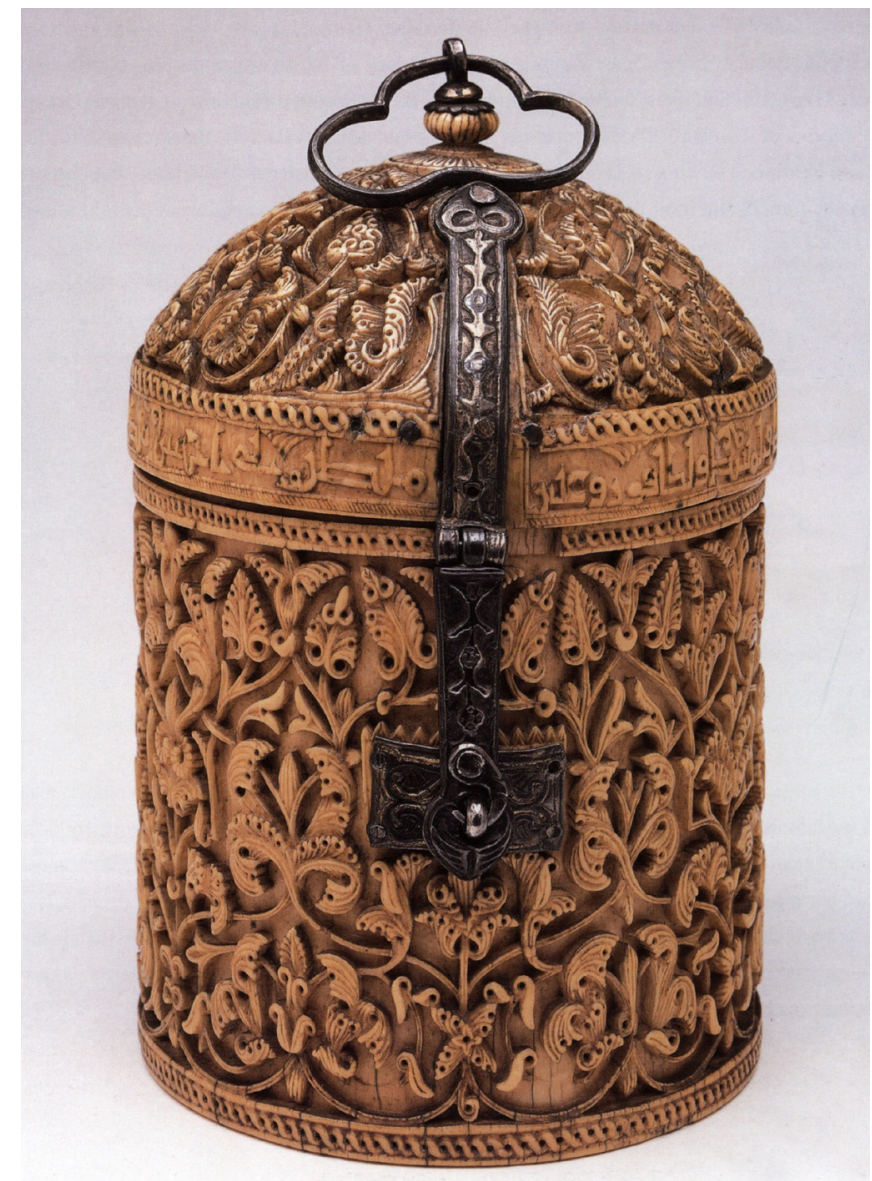

Fig. 8. Píxide, Hispanic Society of America, Nueva York, h. 968 (Foto: P. LENAGHAN, The Hispanic Society of America: Tesoros, Madrid, 2000, p. 127). 